\title{
A STATISTICAL ANALYSIS OF THE HETEROGENEITY OF INHERITED DISEASES ${ }^{1}$
}

\author{
Norikazu YASUDA \\ Division of Genetics, National Institute of Radiological Sciences, \\ Chiba, 260 Japan
}

\begin{abstract}
Summary Heterogeneity of inherited diseases could statistically be demonstrated by utilizing a concept of sporadic cases. A model of segregation analysis based on family data was implemented to derive formulae of estimating the proportion of sporadic cases. With an illustrative example of congenital deafness, it is shown that the estimate of the proportion of sporadic cases is rather sensitive to the probability of ascertainment or the method of family selection. While an assumption of single ascertainment leads to an upper limit of the proportion of sporadic cases, another extreme under complete ascertainment yields a lower one. Between two extremes the estimated proportion of sporadics changes nearly linearly for a given set of family data. A proper estimate of the ascertainment probability therefore would be desirable for an appropriate evaluation of the proportions of sporadic cases. When the probability of ascertainment was not available, the proportion of sporadic cases were unable to be estimated properly. However, a suggestion made for accepting hypothesis of no sporadics unless the test was significant under the assumption of single ascertainment. Alternatively, if the test was significant under the assumption of complete ascertainment, it indicates that there would be genetic heterogeneities.
\end{abstract}

\section{INTRODUCTION}

It has become ubiquitous to point out that any inherited disorder may be produced by more than one genotype. The significances of genetic heterogeneity are manifold. Clinically, an appreciation has important diagnostic value, since diagnosis by age of onset, severity and some other specific features defines our approach to treatment and counseling, to these matters as well. Scientifically, elucidation of the mechanism of heterogeneity has already begun to tell us enormous polymorphisms in which the human genome can be modified and the relatively small

Received May 28,1980

${ }^{1}$ Supported in part by grants from Ministry of Health and Welfare, Japan. 
number of ways that such genetic variation can be expressed phenotypically. Heterogeneity is very often defined using chemical or biochemical assays such as identification of compounds in blood and urine, molecular hybridization analyses, enzyme activity assay, protein characterization and so on.

Genetic methods by all means have been important in demonstrating heterogeneity. The chance marriage of two individuals each affected with autosomal recessively inherited deafness gave birth to none of deaf offsprings (Kraatz, 1925), demonstrating conclusively that the mutations that produced deafness in the two parents were different and probably nonallelic. Linkage study has also revealed heterogeneity in hereditary elliptocytosis into two forms: one closely linked to the $\mathrm{Rh}$ blood groups, the other not (Morton, 1956). Complementation in mixed cells of heterokaryons is an another way of demonstrating heterogeneity (eg. Willard et al., 1978). In several instances, heterogeneity was suggested by different modes of inheritance of phenotypically similar disorders.

The objects of this paper are to summarizes succinctly statistical methods of analyzing heterogeneity of inherited disorders based on family data. The analysis utilizes a concept of sporadic cases introduced first by Haldane (1949) and implemented in segregation analysis by Morton (1959).

\section{CONCEPT AND TERMINOLOGY}

Haldane (1949) emphasized that sibships containing only one affected individual should receive separate treatment from those with two or more affected individuals because single, or as he called it sporadic case of a given condition could occur not as the result of Mendelian segregation for the major gene known to cause the condition. These sporadic cases could have a variety of causes, such as mutations, phenocopies resulting from environmental causes and determined by a mimicking polygenic complex rather than the major gene (Wright, 1934), technical or diagnostic errors, extramarital conceptions, rare instances of heterozygous expression of a recessive gene, chromosomal nondisjunction, or complex genetic mechanisms. All these are likely to be rare events. Thus the probability of a sporadic case in any given family is in general low enough to make it very unlikely that two such cases occur in one family. Thus families with one affected offspring, called either simplex in which there are normal sibling(s) or uniplex where he(she) is an only child, are mixture of sporadic cases and chance isolated case, instance of Mendelian segregation for the relevant gene. Families with two or more affected offsprings, called multiplex are however almost certainly the result of Mendelian segregation for the major gene. The term familial case usually infers a multiple occurrence of affected persons within a pedigree. Here we shall use it interchangeably with multiplex because of interest to siblings. Although such a distinction is difficult or impractical, the proportion of sporadic cases can be determined statistically. An isolated case 
should never be termed sporadic unless there is reason to believe that it is not chanceisolated, namely, sporadic cases of different origin from familial cases.

If both sporadic and familial cases are rare and uncorrelated in occurrence, and if the recurrence rate is very small for sporadic cases, then multiplex families will consist almost exclusively of familial cases. We assume that any sibship with two or more affected is familial sibships which may happen to have only one affected. We therefore analyze simplex and multiplex families separately and attribute any excess of affected in the latter to sporadics.

\section{SEGREGATION MODEL}

Among models of segregation analysis developed by Morton $(1959,1969)$, the following one is pertinent to estimate the proportion of sporadic cases; a model of incomplete ascertainment where families are selected through affected offspring(s). Sporadic cases make up a proportion $\mathrm{x}$ of all cases in the population, and simplex families with sporadic cases constitute a proportion $w$ of families of size $s$ with $r$ affected children. Excluding sporadic cases, the mean number of affected children in a sibship of size $s$ with at least one member affected is $\bar{r}=s p /\left[1-(1-p)^{s}\right]$ where $p$ is the segregation frequency. The proportion of sporadic cases ( $\mathrm{x}$ ) among affected offspring in families of size $s$ is therefore

$$
x=\frac{w \cdot 1}{w \cdot 1+(1-w) \cdot \bar{r}}
$$

or, substituting for $\overline{\mathrm{r}}$,

$$
w=\frac{x s p}{x s p+(1-x)\left[1-(1-p)^{s}\right]} .
$$

Since the probability of ascertained simplex families of size $s$ among those having at least one affected offspring is a sum of those due to sporadics and chance isolated, probability of the latter being $\mathrm{sp}(1-\mathrm{p})^{\mathrm{s}-1} /\left[1-(1-\mathrm{p})^{\mathrm{s}}\right]$, we have

$$
\mathrm{P}(\mathrm{r}=1)=\mathrm{k} \pi\left[\mathrm{w}+(1-\mathrm{w}) \frac{\mathrm{sp}(1-\mathrm{p})^{\mathrm{s}-1}}{1-(1-\mathrm{p})^{\mathrm{s}}}\right]
$$

in which $\pi$ is the probability of ascertainment. For multiplex families, the probability is

$$
\begin{aligned}
P(r) & =k(1-w)-\frac{{ }_{s} C_{r} p^{r}(1-p)^{s-r}\left[1-(1-\pi)^{r}\right]}{1-(1-p)^{s}} \\
(r & =2,3, \ldots, s)
\end{aligned}
$$

where $1-(1-\pi)^{\mathrm{r}}$ is the probability of ascertainment of families with $\mathrm{r}$ affected offsprings. 
Noting that $\mathrm{P}(1)+\mathrm{P}(2)+\ldots+\mathrm{P}(\mathrm{s})=1$, we obtain

$$
\mathrm{k}=\frac{\mathrm{xsp}+(1-\mathrm{x})\left[1-(1-\mathrm{p})^{\mathrm{s}}\right]}{\mathrm{xsp} \pi+(1-\mathrm{x})\left[1-(1-\mathrm{p} \pi)^{\mathrm{s}}\right]}
$$

where $1 / \mathrm{k}$ is in fact the probability of an ascertained family of size $\mathrm{s}$ among segregating families. The distribution of $r$ affected in ascertained families of size $s$ is therefore given by

$$
\mathrm{P}(\mathrm{r}=1)=\frac{\mathrm{sp} \pi\left[\mathrm{x}+(1-\mathrm{x})(1-\mathrm{p})^{\mathrm{s}-1}\right]}{\mathrm{xsp} \pi+(1-\mathrm{x})\left[1-(1-\mathrm{p} \pi)^{\mathrm{s}-1}\right]}
$$

and

$$
\begin{aligned}
P(r) & =\frac{(1-x)_{s} C_{r} p^{r}(1-p)^{s-r}\left[1-(1-\pi)^{r}\right]}{x \operatorname{sp} \pi+(1-x)\left[1-(1-p \pi)^{s-1}\right]} \\
(r & =2,3, \ldots, s) .
\end{aligned}
$$

In case of a single ascertainment, the probability of ascertainment becomes zero since all probands are excluded from the sample in analysis (Yasuda and Saito, 1980). The probabilities are then

$$
P(r=1)=x+(1-x)(1-p)^{s-1}
$$

and

$$
\begin{aligned}
P(r)= & (1-x)_{s-1} C_{r-1} p^{r-1}(1-p)^{s-r} \\
& (r=2,3, \ldots, s)
\end{aligned}
$$

Note here that families selected through an affected child (proband) could be treated as a sample taken by complete ascertainment through parent if probands are removed from the material.

\section{STATISTICAL METHODS}

Gathering families contained $r$ affected in sibling with the size $s$ through $a$ probands make them feasible to score the observed number, $n_{s r}$. A table of $n_{8 r}$ has been called a SR table. The our position is to test a genetic hypothesis from which the frequency of segregation derives as $p=1 / 4$ for both parents being normal, and $p=1 / 2$ for one parent be normal and the other being affected. The probability of ascertainment $(\pi)$ is usually unknown unless probands were defined explicity.

Knowing $\mathrm{p}$ and $\pi$, however, a genetic hypothesis of no sporadic case may be tested as follows. Applying a method of maximum likelihood scoring upon the model (1) and (2), the score $U(x)$ and the information $K(x)$ are 


$$
U(x)=\sum_{s} u_{s}(x) \quad \text { and } \quad K(x)=\sum_{s} k_{s}(x)
$$

where

$$
\mathrm{u}_{\mathrm{s}}(\mathrm{x})=\frac{1}{(1-\mathrm{x})} \cdot\left[\frac{\mathrm{n}_{\mathrm{sl}}}{\mathrm{x}+(1-\mathrm{x})(1-\mathrm{p})^{\mathrm{s}-1}}-\frac{\mathrm{sp} \pi \mathrm{n}_{\mathrm{s}}}{\mathrm{xsp} \pi+(1-\mathrm{x})\left[1-(1-\mathrm{p} \pi)^{\mathrm{s}}\right]}\right]
$$

and

$$
k_{s}(x)=\frac{1}{(1-x)} \cdot \frac{s p \pi\left[1-(1-p \pi)^{s}-s \pi p(1-p)^{s-1}\right]}{\left[x+(1-x)(1-p)^{s-1}\right]\left[x s p \pi+(1-x)\left\{1-(1-p \pi)^{s}\right\}\right]^{2}}
$$

\begin{tabular}{|c|c|c|c|c|c|c|c|c|}
\hline \multirow[b]{2}{*}{$\mathbf{8}$} & \multirow[b]{2}{*}{$1 /(1-p)^{s-1}$} & \multicolumn{5}{|c|}{$\operatorname{sp} \pi /\left[1-(1-p \pi)^{s}\right]$} & \multirow[b]{2}{*}{1.0} & \multirow[b]{2}{*}{$\pi / s$} \\
\hline & & 0.2 & 0.4 & 0.5 & 0.6 & 0.8 & & \\
\hline $\begin{array}{l}2 \\
3 \\
4 \\
5\end{array}$ & $\begin{array}{l}1.33333 \\
1.77777 \\
2.37037 \\
3.16049\end{array}$ & $\begin{array}{l}1.02564 \\
1.05170 \\
1.07820 \\
1.10512\end{array}$ & $\begin{array}{l}1.05263 \\
1.10701 \\
1.16312 \\
1.22097\end{array}$ & $\begin{array}{l}1.06666 \\
1.13609 \\
1.20826 \\
1.28312\end{array}$ & $\begin{array}{l}1.08108 \\
1.16618 \\
1.25524 \\
1.34820\end{array}$ & $\begin{array}{l}1.11111 \\
1.22950 \\
1.35501 \\
1.48738\end{array}$ & $\begin{array}{l}1.14285 \\
1.29729 \\
1.46285 \\
1.63892\end{array}$ & \\
\hline $\begin{array}{r}6 \\
7 \\
8 \\
9 \\
10\end{array}$ & $\begin{array}{l}4.21399 \\
5.61865 \\
7.49154 \\
9.98872 \\
13.3182\end{array}$ & $\begin{array}{l}1.13246 \\
1.16023 \\
1.18842 \\
1.21703 \\
1.24606\end{array}$ & $\begin{array}{l}1.28052 \\
1.34175 \\
1.40466 \\
1.46919 \\
1.53534\end{array}$ & $\begin{array}{l}1.36065 \\
1.44079 \\
1.52348 \\
1.60865 \\
1.69623\end{array}$ & $\begin{array}{l}1.44497 \\
1.54542 \\
1.64946 \\
1.75693 \\
1.86770\end{array}$ & $\begin{array}{l}1.62633 \\
1.77151 \\
1.92255 \\
2.07904 \\
2.24058\end{array}$ & $\begin{array}{l}1.82477 \\
2.01958 \\
2.22250 \\
2.43265 \\
2.64918\end{array}$ & 10 \\
\hline $\begin{array}{l}11 \\
12 \\
13 \\
14 \\
15\end{array}$ & $\begin{array}{l}17.7577 \\
23.6769 \\
31.5692 \\
42.0923 \\
56.1231\end{array}$ & $\begin{array}{l}1.27551 \\
1.30537 \\
1.33564 \\
1.36632 \\
1.39740\end{array}$ & $\begin{array}{l}1.60305 \\
1.67231 \\
1.74306 \\
1.81527 \\
1.88891\end{array}$ & $\begin{array}{l}1.78615 \\
1.87832 \\
1.97266 \\
2.06907 \\
2.16746\end{array}$ & $\begin{array}{l}1.98160 \\
2.09849 \\
2.21819 \\
2.34053 \\
2.46536\end{array}$ & $\begin{array}{l}2.40673 \\
2.57709 \\
2.75125 \\
2.92881 \\
3.10940\end{array}$ & $\begin{array}{l}2.87126 \\
3.09813 \\
3.32909 \\
3.56349 \\
3.80079\end{array}$ & $\begin{array}{l}11 \\
12 \\
13 \\
14 \\
15\end{array}$ \\
\hline
\end{tabular}

Table 1. Table for calculations of $u_{s}(0)$.

$p=1 / 2$

\begin{tabular}{rrlllllllr}
$s$ & $1 /(1-\mathrm{p})^{\mathrm{s}-1}$ & 0.2 & 0.4 & 0.5 & 0.6 & 0.8 & 1.0 & $\pi / \mathrm{s}$ \\
\hline $\mathbf{2}$ & 2. & 1.05263 & 1.11111 & 1.14285 & 1.17647 & 1.25000 & 1.33333 & 2 \\
3 & 4. & 1.10701 & 1.22950 & 1.29729 & 1.36986 & 1.53061 & 1.71428 & 3 \\
4 & 8. & 1.16312 & 1.35501 & 1.46285 & 1.57915 & 1.83823 & 2.13333 & 4 \\
5 & 16. & 1.22097 & 1.48738 & 1.63892 & 1.80303 & 2.16863 & 2.58064 & 5 \\
6 & 32. & 1.28052 & 1.62633 & 1.82477 & 2.04000 & 2.51745 & 3.04761 & 6 \\
7 & 64. & 1.34175 & 1.77151 & 2.01958 & 2.28846 & 2.88063 & 3.52755 & 7 \\
8 & 128. & 1.40466 & 1.92255 & 2.22250 & 2.54681 & 3.25466 & 4.01558 & 8 \\
9 & 256. & 1.46919 & 2.07904 & 2.43265 & 2.81353 & 3.63664 & 4.50880 & 9 \\
10 & 512. & 1.53534 & 2.24058 & 2.64918 & 3.08720 & 4.02433 & 5.00488 & 10 \\
11 & 1024. & 1.60305 & 2.40673 & 2.87126 & 3.36656 & 4.41602 & 5.50268 & 11 \\
12 & 2048. & 1.67231 & 2.57709 & 3.09813 & 3.65052 & 4.81047 & 6.00146 & 12 \\
13 & 4096. & 1.74306 & 2.75125 & 3.32909 & 3.93815 & 5.20600 & 6.50079 & 13 \\
14 & 8192. & 1.81527 & 2.92881 & 3.56349 & 4.22868 & 5.60439 & 7.00042 & 14 \\
15 & 16384. & 1.88891 & 3.10940 & 3.80079 & 4.52146 & 6.00282 & 7.50022 & 15 \\
\hline
\end{tabular}


Table 2. Values of $\frac{k_{s}(0)}{n_{s}}=\frac{s p \pi\left[1-(1-p \pi)^{s}-s \pi p(1-p)^{s-1}\right]}{(1-p)^{s-1}\left[1-(1-p \pi)^{s}\right]^{2}}$

\begin{tabular}{|c|c|c|c|c|c|c|c|c|}
\hline s $\pi$ & 0.0 & 0.2 & 0.4 & 0.5 & 0.6 & 0.8 & 1.0 & $\pi / \mathrm{s}$ \\
\hline $\begin{array}{l}2 \\
3 \\
4 \\
5\end{array}$ & $\begin{array}{l}0.33333 \\
0.77777 \\
1.37037 \\
2.16049\end{array}$ & $\begin{array}{l}0.31558 \\
0.76361 \\
1.39321 \\
2.27143\end{array}$ & $\begin{array}{l}0.29547 \\
0.74254 \\
1.40417 \\
2.36810\end{array}$ & $\begin{array}{l}0.28444 \\
0.72901 \\
1.40413 \\
2.40890\end{array}$ & $\begin{array}{l}0.27270 \\
0.71323 \\
1.39975 \\
2.44333\end{array}$ & $\begin{array}{l}0.24691 \\
0.67410 \\
1.37582 \\
2.48855\end{array}$ & $\begin{array}{l}0.21768 \\
0.62332 \\
1.32756 \\
2.49373\end{array}$ & $\begin{array}{l}2 \\
3 \\
4 \\
5\end{array}$ \\
\hline $\begin{array}{r}6 \\
7 \\
8 \\
9 \\
10\end{array}$ & $\begin{array}{l}3.21399 \\
4.61865 \\
6.49154 \\
8.98872 \\
12.3182\end{array}$ & $\begin{array}{l}3.48972 \\
5.17282 \\
7.49078 \\
10.6754 \\
15.0427\end{array}$ & $\begin{array}{l}3.75637 \\
5.73856 \\
8.54999 \\
12.5168 \\
18.0908\end{array}$ & $\begin{array}{l}3.88240 \\
6.01943 \\
9.09223 \\
13.4806 \\
19.7137\end{array}$ & $\begin{array}{l}4.00115 \\
6.29488 \\
9.63629 \\
14.4627 \\
21.3863\end{array}$ & $\begin{array}{l}4.20839 \\
6.81526 \\
10.7066 \\
16.4445 \\
24.8205\end{array}$ & $\begin{array}{l}4.35978 \\
7.26862 \\
11.7104 \\
18.3813 \\
28.2644\end{array}$ & $\begin{array}{r}6 \\
7 \\
8 \\
9 \\
10\end{array}$ \\
\hline $\begin{array}{l}11 \\
12 \\
13 \\
14 \\
15\end{array}$ & $\begin{array}{l}16.7577 \\
22.6769 \\
30.5692 \\
41.0923 \\
55.1231\end{array}$ & $\begin{array}{l}21.0232 \\
29.2032 \\
40.3812 \\
55.6448 \\
76.4741\end{array}$ & $\begin{array}{l}25.8968 \\
36.7986 \\
51.9890 \\
73.1141 \\
102.443\end{array}$ & $\begin{array}{l}28.5277 \\
40.9449 \\
58.3841 \\
82.8111 \\
116.947\end{array}$ & $\begin{array}{l}31.2620 \\
45.2822 \\
65.1063 \\
93.0406 \\
132.285\end{array}$ & $\begin{array}{l}36.9457 \\
54.3764 \\
79.2856 \\
114.702 \\
164.841\end{array}$ & $\begin{array}{l}42.7430 \\
63.7560 \\
94.0141 \\
137.297 \\
198.866\end{array}$ & $\begin{array}{l}11 \\
12 \\
13 \\
14 \\
1.5\end{array}$ \\
\hline
\end{tabular}

$p=1 / 2$

\begin{tabular}{|c|c|c|c|c|c|c|c|c|}
\hline$s \backslash \pi$ & 0.0 & 0.2 & 0.4 & 0.5 & 0.6 & 0.8 & 1.0 & $\pi / s$ \\
\hline $\begin{array}{l}2 \\
3 \\
4 \\
5\end{array}$ & $\begin{array}{r}1 . \\
3 . \\
7 . \\
15 .\end{array}$ & $\begin{array}{l}0.99723 \\
3.20257 \\
7.95216 \\
18.0447\end{array}$ & $\begin{array}{l}0.98765 \\
3.40634 \\
9.00404 \\
21.5858\end{array}$ & $\begin{array}{l}0.97959 \\
3.50620 \\
9.56290 \\
23.5367\end{array}$ & $\begin{array}{l}0.96885 \\
3.60292 \\
10.1395 \\
25.5976\end{array}$ & $\begin{array}{l}0.93750 \\
3.77967 \\
11.3267 \\
29.9951\end{array}$ & $\begin{array}{l}0.88888 \\
3.91836 \\
12.5155 \\
34.6305\end{array}$ & 2 \\
\hline $\begin{array}{r}6 \\
7 \\
8 \\
9 \\
10\end{array}$ & $\begin{array}{r}31 . \\
63 . \\
127 . \\
255 . \\
511 .\end{array}$ & $\begin{array}{l}39.3369 \\
84.0722 \\
177.823 \\
373.955 \\
783.736\end{array}$ & $\begin{array}{l}49.3977 \\
110.238 \\
242.390 \\
527.913 \\
1142.15\end{array}$ & $\begin{array}{l}55.0628 \\
125.174 \\
279.540 \\
616.841 \\
1349.36\end{array}$ & $\begin{array}{l}61.1185 \\
141.224 \\
319.506 \\
712.349 \\
1571.11\end{array}$ & $\begin{array}{l}74.2209 \\
176.062 \\
406.004 \\
917.756 \\
2044.26\end{array}$ & $\begin{array}{l}88.2358 \\
213.320 \\
497.882 \\
1133.92 \\
2537.45\end{array}$ & $\begin{array}{r}6 \\
7 \\
8 \\
9 \\
10\end{array}$ \\
\hline $\begin{array}{l}11 \\
12 \\
13 \\
14 \\
15\end{array}$ & $\begin{array}{r}1023 . \\
2047 . \\
4095 . \\
8191 . \\
16383 .\end{array}$ & $\begin{array}{l}1638.95 \\
3422.09 \\
7136.54 \\
14867.4 \\
30944.3\end{array}$ & $\begin{array}{l}2458.70 \\
5271.25 \\
11261.5 \\
23984.2 \\
50934.7\end{array}$ & $\begin{array}{l}2931.93 \\
6335.38 \\
13624.8 \\
29179.4 \\
62257.7\end{array}$ & $\begin{array}{l}3436.03 \\
7462.95 \\
16115.1 \\
34623.4 \\
74059.2\end{array}$ & $\begin{array}{l}4502.50 \\
9828.70 \\
21299.9 \\
45879.7 \\
98314.2\end{array}$ & $\begin{array}{l}5604.47 \\
12254.9 \\
26584.9 \\
57298.4 \\
122827 .\end{array}$ & $\begin{array}{l}11 \\
12 \\
13 \\
14 \\
15\end{array}$ \\
\hline
\end{tabular}

In which $n_{s 1}$ and $n_{s}$ are respectively the number of simplex family with sibship size $\mathrm{s}$ and the observed number of family whose size is $\mathrm{s}$. Tables 1 and 2 are prepared for computation of $u_{s}(0)$ and $k_{s}(0)$, respectively, for $p=1 / 4$ and $1 / 2, s=2, \ldots, 15$, and $\pi=0,0.2,0.4,0.5,0.6,0.8$ and 1.0 .

Method 1. The proportion of sporadic cases could be obtained, with the standard error, from

$$
\mathrm{x}_{1}=\mathrm{U}(0) / \mathrm{K}(0) \pm \sqrt{1 / \mathrm{K}(0)} .
$$

A test of the genetic hypothesis of no sporadics, i.e. $\mathrm{x}=0$ is made by a quantity

$$
\mathrm{X}^{2}=[\mathrm{U}(0)]^{2} / \mathrm{K}(0)
$$


that distributes asymtotically as a chi-square variate with one degree of freedom. A test of heterogeneity among $x$ 's could be performed by a chi-square variate

$$
\mathrm{X}_{\mathrm{het}}{ }^{2}=\sum_{\mathrm{s}} \mathrm{u}_{\mathrm{s}}{ }^{2}\left(\mathrm{x}_{1}\right) / \mathrm{k}_{\mathrm{s}}\left(\mathrm{x}_{1}\right)-\left[\mathrm{U}\left(\mathrm{x}_{1}\right)\right]^{2} / \mathrm{K}\left(\mathrm{x}_{1}\right)
$$

with the degrees of freedom being the number of outcomes of $\mathrm{s}$ minus one. Method 2. An alternative estimate may be obtained by

$$
\mathrm{x}_{2}=\sum_{\mathrm{s}} \mathrm{x}_{\mathrm{s}} \mathrm{k}\left(\mathrm{x}_{\mathrm{s}}\right) / \mathrm{K}\left(\mathrm{x}_{\mathrm{s}}\right)
$$

where $x_{s}$ 's respectively satisfy $u_{s}(x)=0$ or

$$
\mathrm{x}_{\mathrm{s}}=\frac{\mathrm{n}_{\mathrm{s} 1} \mathrm{C}_{\mathrm{s} 1}-\mathrm{n}_{\mathrm{s}} \mathrm{C}_{\mathrm{s}}}{-\mathrm{n}_{\mathrm{s} 1} \mathrm{D}_{\mathrm{s} 1}+\mathrm{n}_{\mathrm{s}} \mathrm{D}_{\mathrm{s}}}
$$

In which $\mathrm{C}_{\mathrm{s}_{1}}=1-(1-\mathrm{p} \pi)^{\mathrm{s}}, \mathrm{C}_{\mathrm{s}}=\mathrm{s} \pi \mathrm{p}(1-\mathrm{p})^{\mathrm{s}-1}, \mathrm{D}_{\mathrm{s}_{1}}=(1-\mathrm{p} \pi)^{\mathrm{s}}+\mathrm{sp} \pi-1$ and $\mathrm{D}_{\mathrm{s}}=$ $\mathrm{s} \pi \mathrm{p}\left[1-(1-\mathrm{p})^{\mathrm{s}-1}\right]$ have been tabulated en bloc in Tables 3 and 4 for respectively $\mathrm{p}=1 / 4$ and $1 / 2$, and $s=2, \ldots, 15$ and $\pi=0 ., 0.2,0.4,0.5,0.6,0.8$ and 1.0. Note here that for a given sibship size $\mathrm{s}$ if either there is no simplex family $\left(\mathrm{n}_{\mathrm{s}_{1}}=0\right)$ or solely simplex families $\left(\mathrm{n}_{\mathrm{s} 1}=\mathrm{n}_{\mathrm{s}}\right) \mathrm{x}_{\mathrm{s}}$ can not be estimated by this method since no information is contained on the proportion of sporadic cases in such data. The chi-square tests mentioned in method 1 may be made by substituting $x_{2}$ instead $x_{1}$ for (9) and (10), respectively.

Method 3. The above two estimates are in fact first approximations in interactive processes of a method of maximum likelihood scoring. A maximum likelihood solution $\left(\mathrm{x}_{3}\right)$ is obviously desirable but it requires cumbersome computations which might give a feel to disincline to do so unless electronic computer be available.

In case of a single ascertainment $(\pi=0)$, the scores are, from (3) and (4),

$$
u_{s}(x)=\frac{1}{(1-x)}\left[\frac{n_{s 1}}{x+(1-x)(1-p)^{s-1}}-n_{s}\right]
$$

and

$$
\mathrm{k}_{\mathrm{s}}(\mathrm{x})=\frac{\mathrm{n}_{\mathrm{s}}\left[1-(1-\mathrm{p})^{\mathrm{s}-1}\right]}{(1-\mathrm{x})\left[\mathrm{x}+(1-\mathrm{x})(1-\mathrm{p})^{\mathrm{s}-1}\right]}
$$

Also,

$$
\mathrm{x}_{\mathrm{s}}=1-\frac{1-\frac{\mathrm{n}_{\mathrm{s} 1}}{\mathrm{n}_{\mathrm{s}}}}{1-(1-\mathrm{p})^{\mathrm{s}-1}}
$$

\section{A WORKING EXAMPLE}

Furusho and Yasuda (1973) have reported on congenital deafness in Kanto 


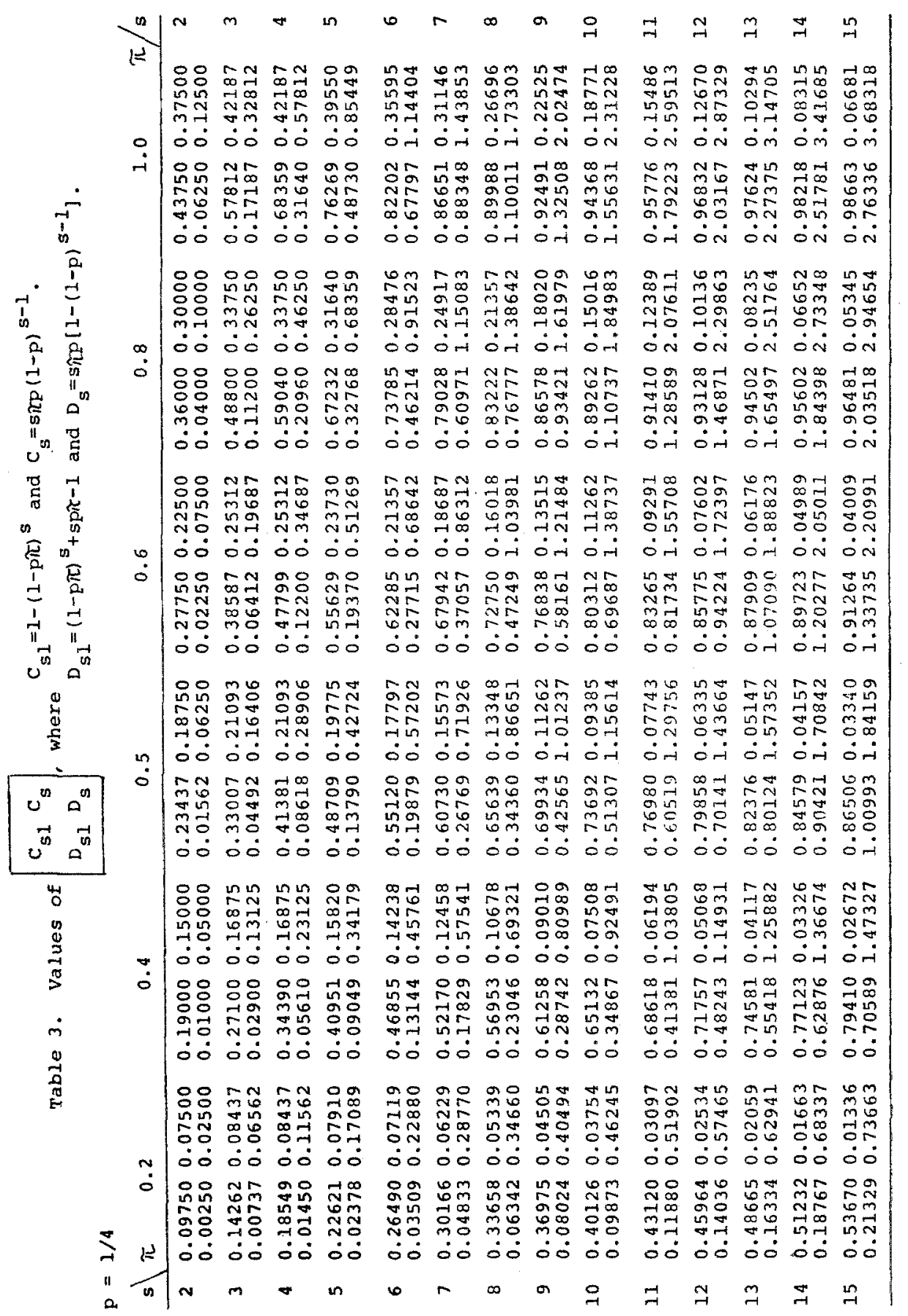

Jpn. J. Human Genet. 


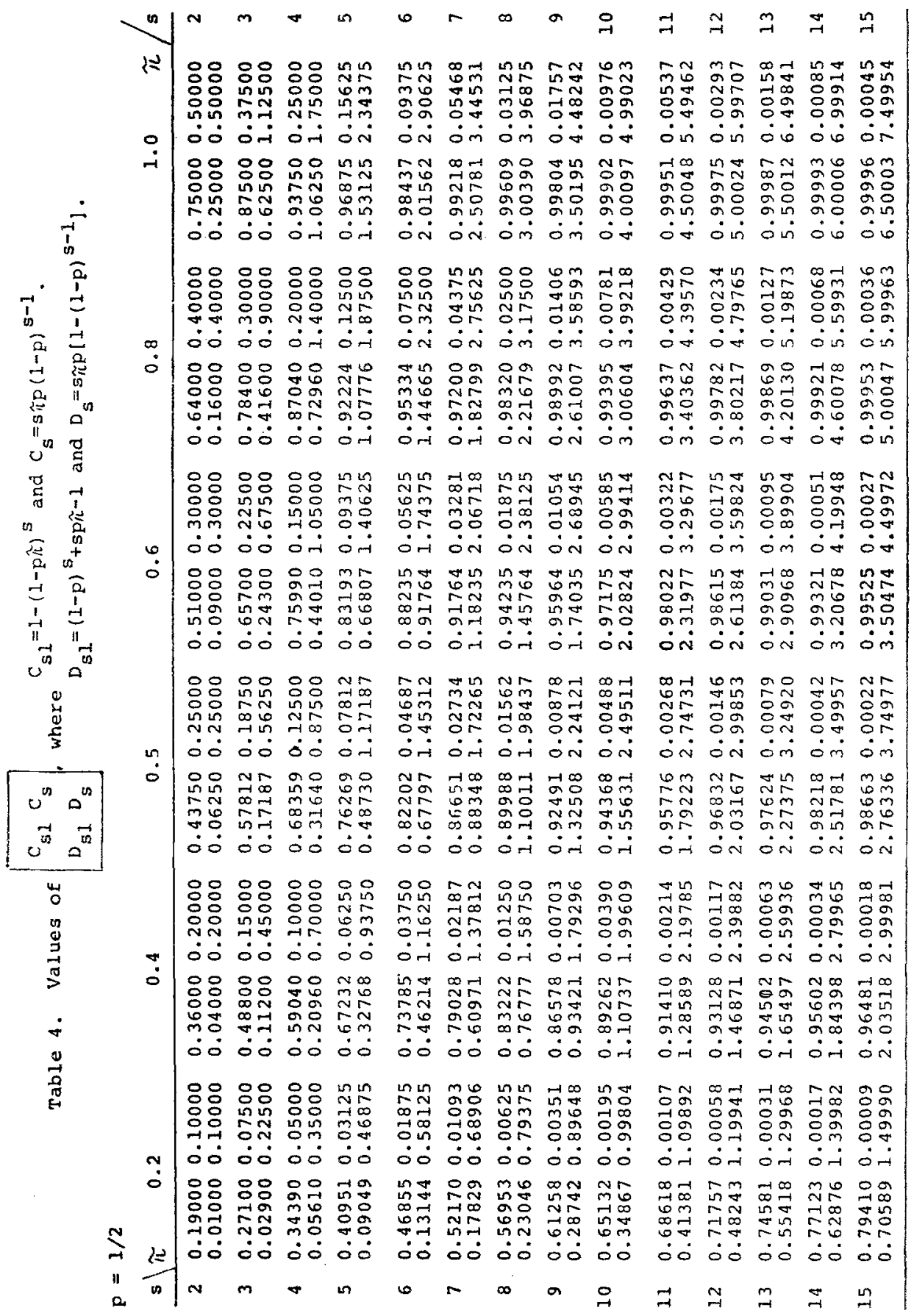

Vol. 26, No. 1, 1981 
Table 5. Estimation of the proportion of sporadic cases in congenital deaf born to normal parents in Kanto district, Japan (Method 1).

$\mathrm{p}=1 / 4$ and $\pi=0.5$

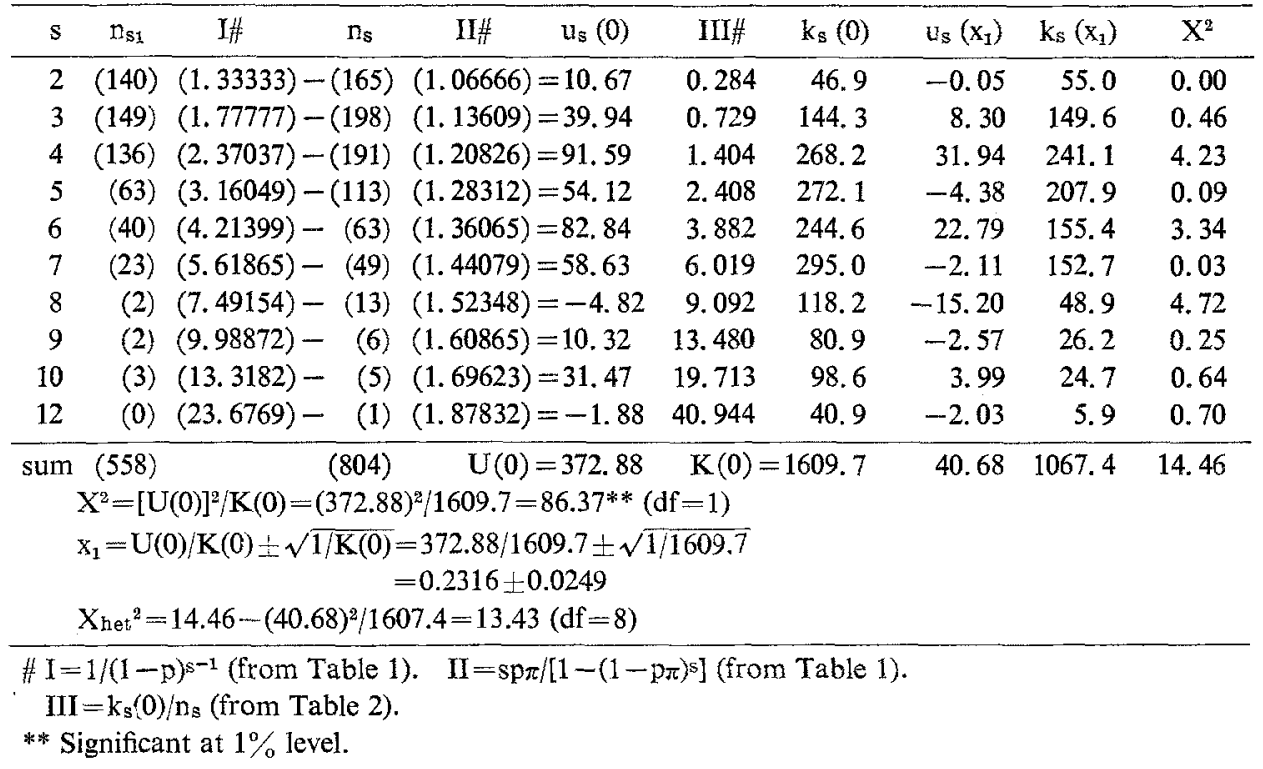

district of Japan, which may serve as an illustration not only for testing the hypothesis of no sporadics, but also for estimating the proportion of sporadic cases. The observed distributions of affected persons among families have been summarized in SR tables, one for congenital deaf born to normal parents (Table 4 in the paper cited) and the other for those born to normal and affected parents (Table 5 in the paper cited). The paper also included a distribution of probands among affected siblings (RA table) so that the ascertainment probability could be estimated as $\pi=0.5011 \pm 0.0289$ (Yasuda, 1979). For the illustrative purpose, we take the value $\pi=0.5$.

Table 5 depicts method 1 for intercross families not only for testing the hypothesis that $p=1 / 4$ and $x=0$, but also for estimating the proportion of sporadic cases. In column 2 is the observed number of simplex family $\left(\mathrm{n}_{\mathrm{s} 1}\right)$ for a given size of siblings, and in column $4 n_{s}$ designates the observed number of family with the size of sibship s. Columns 3 and 5 are respectively found in Table 1 for $p=1 / 4$ and $\pi=0.5$. Column 7 is from Table 2 for $p=1 / 4$ and $\pi=0.5$. Since the data yield $U(0)=372.88$ and $K(0)=1609.8$, the value of chi-square for a test of the genetic hypothesis that $\mathrm{x}=0$ becomes $(372.88)^{2} / 1609.7=86.37$ (formula 9 ) with one degree of freedom being highly significant. An estimate of the proportion of sporadic cases is then $\mathrm{x}_{1}=$ $0.2316 \pm 0.0249$ (formula 8). Thus as shown in columns 9 and 10 of Table 5, we obtain $U\left(x_{1}\right)=40.68$ and $K\left(x_{1}\right)=1067.4$. To calculate respectively $u_{s}(x)$ and $k_{s}(x)$ 
Table 6. Estimation of the proportion of sporadic cases in congenital deaf born to normal parents in Kanto district, Japan (Method 2).

$\mathrm{p}=1 / 4$ and $\pi=0.5$

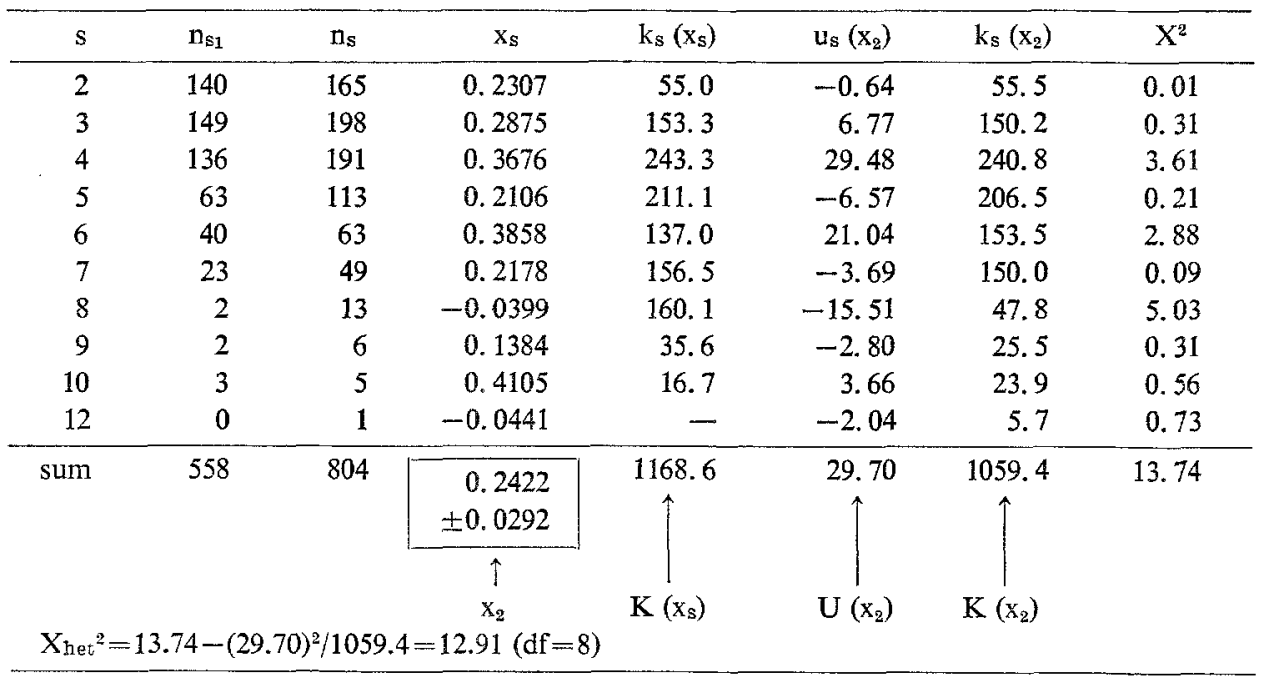

from formulae (6) and (7), the following relations may be useful to utilize the values in Table 3:

$$
\begin{aligned}
& \mathrm{sp} \pi=\mathrm{C}_{\mathrm{s}}+\mathrm{D}_{\mathrm{s}}, \\
& 1-(1-\mathrm{p} \pi)^{\mathrm{s}}=\mathrm{C}_{\mathrm{s} 1}
\end{aligned}
$$

and $\mathrm{sp} \pi\left[1-(1-\mathrm{p} \pi)^{\mathrm{s}}-\mathrm{s} \pi \mathrm{p}(1-\mathrm{p})^{\mathrm{s}-1}\right]=\left(\mathrm{C}_{\mathrm{s} 1}-\mathrm{C}_{\mathrm{s}}\right)\left(\mathrm{C}_{\mathrm{s}}+\mathrm{D}_{\mathrm{s}}\right)$.

For $s=2, p=1 / 4$ and $\pi=0.5$, Table 3 gives en bloc $C_{s 1}=0.23437, C_{s}=0.18750$, $\mathrm{D}_{\mathrm{s}_{1}}=0.01562$ and $\mathrm{D}_{\mathrm{s}}=0.06250$ so that the present materials yield $\mathrm{u}_{\mathrm{s}=2}(\mathrm{x}=0.2316)=$ $[1 /(1-0.2316)][140 /(0.2316+(1-0.2316) / 1.3333)-2 \times 0.25 \times 0.5 \times 165 /(0.2316 \times 2 \times$ $0.25 \times 0.5+(1-0.2316) \times(0.23437)]=1.30141[140 / 0.80791-0.25 \times 165 / 0.23799]=$ -0.05 and $\mathrm{k}_{\mathrm{s}=2}(\mathrm{x}=0.2316)=165 \times 1.30141 \times\left[0.01172 /\left(0.80791 \times 0.23799^{2}\right)\right]=55.0$. The value of chisquare for a test of heterogeneity among $x$ 's becomes $\mathrm{X}_{\text {het }}^{2}=14.46$ $-(40.68)^{2} / 1067.4=13.43$ (formula (10)) with $10-2=8$ degrees of freedom, which is not significant $(0.1<\mathrm{P}<0.2)$.

Alternative procedure (method 2) was shown in Table 6. Calculation of $\mathrm{x}_{s}$, the proportion of sporadics for a given size of sibship s, made them simpler with Table 3. The values of C's and D's are respectively found en bloc in Table 3 , for instance when $s=2, p=1 / 4$ and $\pi=0.5$, we obtain $C_{s_{1}}=0.23437, C_{s}=0.18750, D_{s_{1}}=0.01562$ and $D_{\mathrm{s}}=0.06250$. Thus in the present data

$$
\mathrm{X}_{\mathrm{s}=2}=\frac{(140)(0.23437)-(165)(0.18750)}{-(140)(0.01562)+(165)(0.06250)}=0.2307
$$


and $k_{s}\left(x_{s}=0.2307\right)=55.0$ (formula (7)). Method 2 thus yields $x_{2}=0.2422 \pm 0.0292$ so that $\mathrm{U}\left(\mathrm{x}_{2}\right)=29.70$ and $\mathrm{K}\left(\mathrm{x}_{2}\right)=1059.4$. The chi-square value for a test of heterogeneity becomes $\mathrm{X}_{\mathrm{het}}{ }^{2}=13.74-(29.70)^{2} / 1059.4=12.91$, practically the same the one obtained by method 1 .

A more elaborated estimate obtained by a method of maximum likelihood scoring was $x_{3}=0.2709 \pm 0.0310$. The above conventional estimates, $x_{1}$ and $x_{2}$, are in fact within the standard error of the maximum likelihood solution. An independent estimate of the proportion of sporadic cases has also been derived from inbreeding study as $\mathrm{x}_{4}=0.2456 \pm 0.0572$ (Furusho and Yasuda, 1973). This, too, is in a good

Table 7. Estimation of the proportion of sporadic cases in congenital deaf born to normal and affected parents in Kanto district of Japan (Method 1).

$$
\mathrm{p}=1 / 2 \text { and } \pi=0.5
$$

\begin{tabular}{|c|c|c|c|c|c|c|c|c|c|}
\hline s & $n_{s_{1}}$ & I\# & $n_{s}$ & $\mathrm{us}_{\mathrm{s}}(0)$ & $\mathrm{III} \#$ & $k_{\mathbb{s}}(0)$ & $u_{\mathrm{s}}\left(\mathrm{x}_{1}\right)$ & $k s\left(x_{2}\right)$ & $X^{2}$ \\
\hline 2 & (6) & (2.) & $-(6)$ & $(1.1428)=5.14$ & 0.979 & 5.9 & 4.73 & 5.79 & 3.86 \\
\hline 3 & (6) & (4.) & $-(8)$ & $(1.2972)=13.62$ & 3.506 & 28.0 & 10.21 & 23.69 & 4. 40 \\
\hline 4 & $(0)$ & (8.) & $-(2)$ & $(1.4628)=-2.93$ & 9.562 & 19.1 & -3.06 & 12.69 & 0.74 \\
\hline 5 & (1) & (16.) & $-(6)$ & $(1.6389)=6.17$ & 23.536 & 141.2 & -2.00 & 65.46 & 0.06 \\
\hline 7 & (1) & (64.) & $-(2)$ & $(2.0195)=59.96$ & 125.174 & 250.3 & 8.04 & 40.83 & 1.58 \\
\hline 9 & $(0)$ & (256.) & $-(1)$ & $(2.4326)=-2.43$ & 616.841 & 616.8 & -2.37 & 27.05 & 0.21 \\
\hline sum & (14) & & (25) & $\mathrm{U}(0)=79.53$ & $\mathrm{~K}(0)$ & 1061.3 & $\begin{array}{l}15.55 \\
\| \\
U\left(\mathrm{x}_{1}\right)\end{array}$ & $\begin{array}{c}175.51 \\
\text { K. }\left(x_{1}\right)\end{array}$ & 10.85 \\
\hline \multicolumn{10}{|c|}{$\mathrm{X}^{2}=(79.53)^{2} / 1061.3=5.96^{*}(\mathrm{df}=1)$} \\
\hline \multicolumn{10}{|c|}{$x_{1}=0.0749 \pm 0.0307$} \\
\hline \multicolumn{10}{|c|}{$\mathrm{X}_{\text {het }}{ }^{2}=10.85-(15.55)^{2} / 175.51=9.87(\mathrm{df}=4)$} \\
\hline
\end{tabular}

Table 8. Estimation of the proportion of sporadic cases in congenital deaf born to normal and affected parents in Kanto district of Japan (Method 2). $\mathrm{p}=1 / 2$ and $\pi=0.5$

\begin{tabular}{|c|c|c|c|c|c|c|c|}
\hline $\mathrm{s}$ & $n_{s_{1}}$ & $\mathrm{n}_{\mathrm{s}}$ & $x_{s}$ & $k_{s}\left(x_{s}\right)$ & $u_{s}\left(x_{2}\right)$ & $k_{s}\left(x_{2}\right)$ & $X^{2}$ \\
\hline 2 & 6 & 6 & 1.0000 & - & 4.37 & 5.8 & 3.29 \\
\hline 3 & 6 & 8 & 0.5625 & 17.6 & 7.73 & 20.8 & 2.87 \\
\hline 4 & 0 & 2 & -0.1428 & - & -3.22 & 9.5 & 1.09 \\
\hline 5 & 1 & 6 & 0.0449 & 83.5 & -4.82 & 42.2 & 0.55 \\
\hline 7 & 1 & 2 & 0.3168 & 10.0 & 3.01 & 20.9 & 0.43 \\
\hline 9 & 0 & 1 & -0.0039 & - & -2.36 & 12.4 & 0.45 \\
\hline sum & 14 & 25 & 0.1520 & $\begin{array}{l}111,1 \\
\| \\
\mathrm{K}^{\prime}\left(\mathrm{x}_{\mathrm{s}}\right)\end{array}$ & $\begin{array}{c}4.71 \\
\text { il } \\
\left(x_{2}\right)\end{array}$ & $\begin{array}{l}111.6 \\
\| \\
K_{2}\left(x_{3}\right)\end{array}$ & 8.68 \\
\hline \multicolumn{8}{|c|}{$\begin{array}{l}\mathrm{X}_{2}=0.1520 \pm 0.0949 \\
\mathrm{X}_{\mathrm{het}}{ }^{2}=8.68-(4.71)^{2} / 111.6=8.48(\mathrm{df}=4)\end{array}$} \\
\hline
\end{tabular}


agreement with the others. Taking a mean weighted by $\mathrm{K}$ or a reciprocal of variance for four $x_{1}$ 's, a representative estimate would be $x=0.25 \pm 0.02$. Congenital deafness is thus of $100(1-x)=0.75$ or 75 percent due to recessive genes in the present material.

Backcross material yields $x_{1}=0.0749 \pm 0.0307$ (Table 7), $x_{2}=0.1520 \pm 0.0949$ (Table 8) and a maximum likelihood solution being $x_{3}=0.2121 \pm 0.1058$. Method 1 seems to give an underestimate of $\mathrm{x}$, but the standard error is the smallest. This discrepancy is probably due to a smallness of sample size. We take a point value of weighted mean of three estimates; namely, $x=0.09 \pm 0.03$. Therefore of $100(1-x)=$ 0.91 or 91 percent congenital deafness is due to either dominants or recessives since both modes of inheritance yield segregation frequency to be $1 / 2$ in backcross. Since 75 percent was due to recessive genes unraveled from the analysis of intercross families, the difference $91-75=16$ percent is due to dominant genes. The remaining portions of 9 percent are due to neither recessives nor dominants, and which would include genes due to sex-linkage, more complex genetic mechanisms, sporadics due to unrecognized infection or misclassification, and so on. In Furusho and Yasuda (1973), a ratio of recessives : dominants : sporadics (included sex-linkage) was $71: 17: 12$, while the present re-analysis resulted it $75: 16: 9$. Both ratios by all means agree well each other. Genetic heterogeneity of congenital deafness has been well documented as McKusick (1971) listed 36 recessives, 32 dominants and 6 sex-linked kinds.

\section{DISCUSSION}

For all practical purposes, method 1 would be sufficient for testing hypothesis that there is no sporadics and for estimating proportion of sporadic cases. Backcross data however yield a smaller estimate of $\mathrm{x}$ by method 1 compared to the other methods. This has been attributed to a smallness of sample size, but an alternative explanation would be possible. When an estimate of maximum likelihood was obtained as $\mathrm{x}_{3}=0.2121 \pm 0.1058$ under the hypothesis that $\mathrm{p}=1 / 2$ and $\pi=0.5$, a value of the chi-square for $\mathrm{p}$ became 6.70 with one degree of freedom being statistically significant at five percent level. On the other hand, an estimated frequency of segregation under the hypothesis that $\pi=0.5$ and $x=0$ was $p=0.275 \pm 0.056$. This infers that the backcross data might be explained by no sporadics but incomplete penetrance $(0.275 \pm 0.056) / 0.5=0.55 \pm 0.11$. A joint estimation of $p$ and $x$ with $\pi=0.5$ yields practically the same figures; namely, $p=0.270 \pm 0.087$ and $x=-0.015 \pm$ 0.206. At a glance incomplete penetrance would well explain the backcross data, but it would be not the case. Because analysis of intercross families suggested the existence of non-recessives so that the above statistically superficial finding might be due to bias of sampling such as under-representation of affected siblings if one of parents was affected. Such biases would be serious when the size of sample was small. It would be very careful to accept the hypothesis when two parameters, penetrance and sporadics, were significant. 
Discussions so far made were based on knowing an estimate of the probability of ascertainment. In a many reports probands are not distinguishable from secondary cases, given only affection status in pedigree. Even in the case where the ascertainment probability could be estimated, critiques have been made on assumptions of both independency of probands each other and constancy of the ascertainment probability among affected persons. One way to avoid a nuisance parameter $\pi$ in segregation analysis is to assume that a given data would be an intermediate position between single $(\pi=0)$ and complete $(\pi=1)$ ascertainment as already suggested in analysis of segregation frequency (Smith, 1959). In the working example, for intercross we have $\mathrm{U}(0)=541.74$ and $\mathrm{K}(0)=1366.3$ assumed the single ascertainment so that $\mathrm{x}_{1}=0.396 \pm 0.027$ with $\mathrm{X}^{2}=214.80(\mathrm{df}=1)$ and $\mathrm{X}_{\mathrm{het}}{ }^{2}=13.40(\mathrm{df}=8)$. Also, $\mathrm{x}_{2}=$ $0.411 \pm 0.029$ and $x_{3}=0.418 \pm 0.029$. Estimated proportions of sporadic cases are somewhat twofold the ones obtained previously with $\pi=0.5$. Assuming a complete ascertainment, intercross families yield $\mathrm{U}(0)=161.95$ and $\mathrm{K}(0)=1793.1$ so that $\mathrm{x}_{1}=$ $0.090 \pm 0.023$ with $X^{2}=14.63(\mathrm{df}=1)$ and $\mathrm{X}_{\mathrm{het}}{ }^{2}=11.91(\mathrm{df}=8)$. Also, $\mathrm{x}_{2}=0.062 \pm$ 0.026 and $x_{3}=0.102 \pm 0.029$. An assumption of $\pi=1$ gave a minimum value of the proportion of sporadic cases, but a chi-square test was still statistically significant, indicating that the hypothesis of no sporadics was invalid. That is, the assumption of complete ascertainment would be sufficient for testing the hypothesis of no sporadics because the smallest estimate of $\mathrm{x}$ was obtained under the assumption of complete ascertainment.

As depicted in Fig. 1, estimated proportion of sporadic cases under various values of $\pi$ decreases approximately linearly from a maximum at $\pi=0$ to a minimum

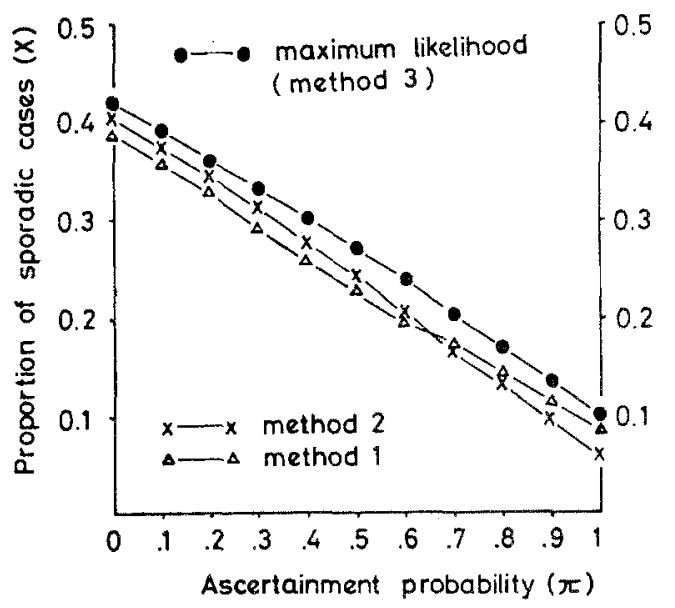

Fig. 1. Estimated proportions of sporadic cases from intercross families of congenital deaf in Kanto district of Japan under the assumption of various values of the ascertainment probability. 


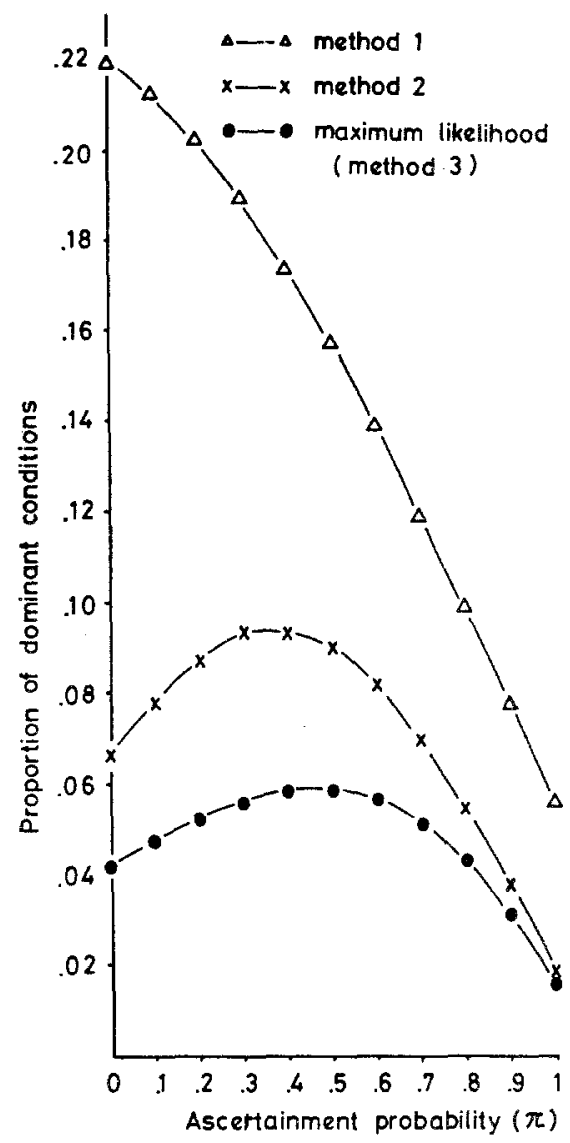

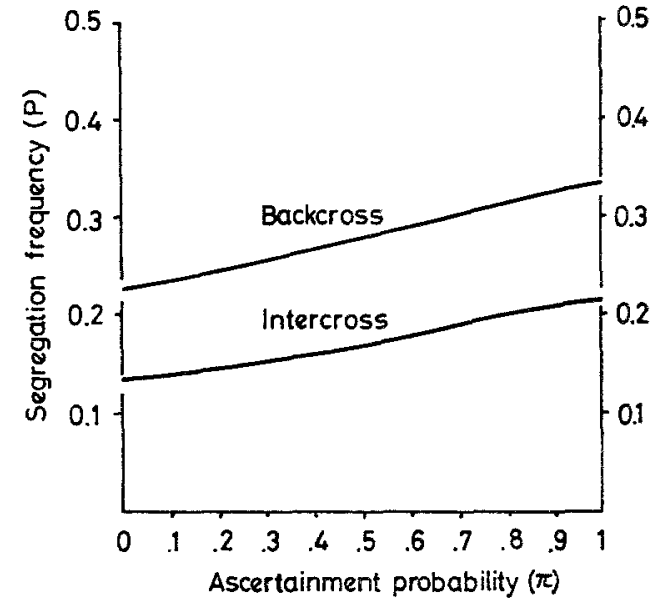

$\uparrow$ Fig. 3. Effects of various values of the ascertainment probability on the segregation frequency in congenital deaf in Kanto district of Japan.

$\leftarrow$ Fig. 2. Proportion of dominant conditions in congenital deaf in Kanto district of Japan under the assumption of various values of the ascertainment probability.

at $\pi=1$ in the present material. A suggestion therefore made for accepting hypothesis of no sporadics unless the test was significant under the assumption of single ascertainment. Alternatively, if the test was significant under complete ascertainment, it indicates that there would be genetic heterogeneities. However, a proper value of $\pi$ would be necessary in order to estimate appropriately the proportion of sporadic cases.

The proportion of dominant conditions was examined for utilizing backcross as well as intercross families. A difference of the estimated proportions of sporadics between backcross and intercross data is an estimated portion of dominant conditions in incomplete ascertainment. As shown in Fig. 2, maximum likelihood solutions gave a maximum at $\pi=0.5$. A conventional method 1 gave the values of dominant conditions from $0.055(\pi=1)$ to $0.290(\pi=0)$, probably because of biases discussed previously. Figure 2 also indicates that a dissecting the proportion of sporadic cases, especially by method 1 , is more sensitive to the probability of ascertainment 
and possible biases introduced in sampling. Intrinsic nature of overestimating the proportion of sporadic cases is once again obvious in the single ascertainment.

In this connection, it would be worthwhile to examine the effect of $\pi$ on the estimate of segregation frequency $p$, since the value of $\pi$ is so often unknown that we must assume a mode of ascertainment in segregation analysis. Figure 3 shows a relation between $\mathrm{p}$ and $\pi$ in both intercross and backcross materials. With estimated segregation frequency by a method of maximum likelihood, an assumption of single ascertainment yielded the smallest value of $p$, increased practically linearly to a maximum at the one obtained under the complete ascertainment. The probability of ascertainment affects the estimates of segregation frequency $p$ and the proportion of sporadic cases $x$ in opposite directions, but the effect seems to be smaller in $p$ than in $\mathrm{x}$.

Thus, if a proper value of the ascertainment probability was not available, it would be practical to perform segregation analysis under the assumption of both single and complete ascertainments. Then following interpretations might be instructive. First, the hypothesis of no sporadics was unable to be rejected statistically, and the observed segregation frequency was compatible to the expected one. We accept the disease be explained by Mendelian genes. Second, no sporadics but the observed segregation frequency was lower than the expected one. Mendelian genes with incomplete penetrance might be an acceptable mechanism. Third, sporadics were statistically significant but the segregation frequency was compatible with the genetic hypothesis. Genetic heterogeneity might be compatible with Mendelian genes. Finally, there were sporadics, and segregation frequency was deviated from the hypothesis. Careful examination would be necessary to reduce any mechanism because of, among other things, sampling biases, smallness of sampling size, diagnosis criteria, selection or wrong hypothesis being tested.

It is hoped that statistical analysis should be in the collation of laboratory or clinical studies or at least should indicate a direction of such approaches. Thereby, evidences could be counterchecked each other.

Acknowledgements I wish to thank Mr. Kenjiro Fukuhisa for his technical assistance in running computer programs on TOSBAC 3400 installed in the National Institute of Radiological Sciences.

\section{REFERENCES}

Furusho, T., and Yasuda, N. 1973. Genetic studies on inbreeding in some Japanese population XIII. A genetic study of congenital deafness. Jpn. J. Hum. Genet. 18: 47-65.

Haldane, J.B.S. 1949. A test for homogeneity of records of familial abnormalities. Ann. Eugen. 14: 339-341.

Kraatz, J.J. 1925. Hereditary deaf mutism. J. Heredity 16: 265-270.

McKusick, V.A. 1971. Nosological tables of hereditary deafness. In Mendelian Inheritance in Man (third ed.). The John Hopkins Univ. Press. pp. xxiii-xxv. 
Morton, N.E. 1956. The detection and estimation of linkage between the genes for elliptocytosis and the Rh blood type. Am. J. Hum. Genet. 8: 80-96.

Morton, N.E. 1959. Genetic tests under incomplete ascertainment. Am. J. Hum. Genet. 11: 1-16.

Morton, N.E. 1969. Segregation analysis. In Computer Application in Genetics (N.E. Morton ed.). The Univ. Hawaii Press. pp. 129-139.

Smith, C.A.B. 1959. A note on the effect of ascertainment on segregation ratios. Ann. Hum. Genet. 23: $311-323$.

Willard, H.F., Mellman, I.S., and Rosenberg, L.E. 1978. Genetic complementation among inherited deficiencies of methylmalonyl-CoA mutase activity: Evidence for a new class of human cobalamin mutant. Am. J. Hum. Genet. 30: 1-13.

Wright, S. 1934. The results of crosses between inbred strains of guinea pigs differing in number of digits. Genetics 19: 537-551.

Yasuda, N. 1979. Estimation of the ascertainment probability of rare diseases. Jpn. J. Hum. Genet. 24: $265-291$.

Yasuda, N., and Saito, N. 1980. The deficiency of 21-hydroxylase as a paradigm of segregation analysis. Jpn. J. Hum. Genet. 25: 319-324. 